\title{
Evaluating the impact of flood inundation with the cloud computing platform over vegetation cover of Ganga Basin during COVID-19
}

\author{
Sukanya Ghosh ${ }^{1}$ (D) Deepak $\operatorname{Kumar}^{1}$ (D) $\operatorname{Rina~Kumari}^{2}$ (D)
}

Received: 13 September 2021 / Revised: 3 January 2022 / Accepted: 4 January 2022 / Published online: 20 January 2022

(C) Korean Spatial Information Society 2022

\begin{abstract}
Around the month of July 2020, the people suffering from the COVID-19 pandemic got added burden of disastrous floods. The current study tries to understand the impact of flood inundation on the vegetation cover across the Ganga Basin with the help of a cloud-based computing platform like Google Earth Engine (GEE) in a near real-time scenario. This offers a semi-automatic scheme with customized algorithms to process the large scale of datasets to further analyze and derive the required information from space-based satellite images like Synthetic Aperture Radar (SAR) images. The direct impact of floods on vegetation cover is assessed with the satellitederived normalized difference vegetation index (NDVI) and enhanced vegetation index (EVI). The results of postflood NDVI and EVI readings showed a considerable reduction due to the protracted flood water submergence. The results show the flood extent maps for the selected regions for the lower Ganga Basin having inundations in parts of Bihar and West Bengal. This affects the settlements, agricultural land, and vegetation cover with damage to the large population. The outcomes of the work may be
\end{abstract}

Deepak Kumar

deepakdeo2003@gmail.com; dkumar12@amity.edu

Sukanya Ghosh

sukanyaghosh772@gmail.com

Rina Kumari

rina.sesd@cug.ac.in

1 Amity Institute of Geoinformatics and Remote Sensing (AIGIRS), Amity University Uttar Pradesh, Sector 125, Gautam Buddha Nagar, Noida 201313, India

2 School of Environment and Sustainable Development (SESD), Central University of Gujarat, Sector-30, Gandhinagar, 382030 Gujarat, India utilized to assess the precise flood-inundated areas at a faster rate to offer a faster response even in the pandemic.

Keywords COVID-19 - Flood inundation · Ganga Basin · Google earth engine $\cdot$ Cloud computing

\section{Introduction}

Flooding brought immense pain and catastrophic economic breakdown during the fight against COVID-19 in the 2020 pandemic outbreak, disrupting every global aspect like international business, supply networks, economic conditions, and commodity prices [1]. The ongoing pandemic, along with the flood has had long-term economic consequences, as well as affecting the health of a substantial segment of the population. Several risk reduction measures are prevalent including social distancing, mass quarantines, cluster lockdowns, extensive travel restrictions, and interferences in transport systems for reducing the impact of a pandemic. These have contributed to the global impact of socio-economic growth and political relations [2]. For the first time in contemporary history, all forms of industries, vehicle movement, and people's activities came to a halt. Since many industries and people's activities have been shut down for a month or longer in many parts of the world, it is believed that the current situation in the environmental spheres is projected to improve [3]. Several environmental assessment studies have recently published preliminary assessments of the impact of lockdown on the water quality of India's inland and coastal waters [4-7]. As per the reports of Indian News sources, the Ganges water has been rejuvenated to a point where it is now potable because of the lockdown. It is stated in recent studies that the water quality of major rivers in India has 
consequently improved during the lockdown period [5]. However, in areas where floods coincided with the epidemic, the situation was disastrous, creating a compound hazard [8]. Contending against the spread of COVID-19 is not the only challenge; enduring monsoon floods have intensified the effects on life and property. The severity of these floods varied greatly from one location to the next, depending on numerous factors like irregular weather patterns and heavy rainfall events. During the last few years, multiple districts in Indian states have experienced severe floods. The Mumbai floods (2005), the Assam floods (2012), the Kedarnath flash floods (2013), the Jhelum floods (2014), the Chennai floods (2015), the Kerala floods (2018), and the Bihar floods (2019) are just a few examples [9].

Although floods are mostly considered a routine affair in several parts of India during monsoon seasons, the Ganga Basin is particularly vulnerable. Most of these areas lie in the state of Bihar and they are frequently inundated due to the bloating of rivers in a neighbouring country (i.e. Nepal) [10]. Every year, this phenomenon devastates the Ganga plains, especially during the monsoon season. This results in displaced people, ruined crops, and dangerous hazards to life and property. Floods are common in the vast Gangetic plains, but the situation has been exacerbated because of the current COVID-19 pandemic.

The Ganga Basin is a part of the Ganga-Brahmaputra lowlands, one of the world's largest basins, which spans China, Nepal, India, and Bangladesh. More than $30 \%$ of the population live in the states of Bihar, Jharkhand, and West Bengal, and these are commonly known as the Lower Ganga Basin. The speedy growth of population and settlements has caused modifications in land use, soil erosion, siltation, all of which have augmented the flood severity. Nevertheless, during recent years, floods have become the most frequent disaster, but the intensified problem is the incidence of the COVID-19 pandemic along with the floods. Consequently, the management of the COVID-19 outbreak along with flood mitigation requires the adoption of new approaches. Although field data with accurate measurements are considered to be more reliable, it is also more time-consuming and cost-intensive [11]. Moreover, field inspections are unfeasible for this period, as social distancing becomes a norm to reduce the potential risks to health and travel costs. Unsuitable approaches for flood mitigation may cause further loss to human beings, property damage, and further spread of COVID-19 [12]. It is observed that devastating effects of floods have been reported in 149 districts throughout the states of Bihar, Assam, West Bengal [13]. The ideal way out is the necessity of robust flood management methods with realtime information, as movement is blocked due to the nationwide lockdown. The sharp rise in flood occurrences in these regions prompted experts to adopt more structured and effective flood management strategies to mitigate the challenges under the guidelines and regulations of COVID19. The challenges highlight the need for geospatial technology coupled with advanced Artificial Intelligence (AI) algorithm approaches to provide an add-on to the process of automation. Technological advancements have accelerated the processing of big spatial datasets with improved accuracies and predictions. There are innumerable applications of $\mathrm{AI}$ in the field of geospatial domain, as well as cloud-based technology. In the meantime, COVID-19 outbreaks may be mapped, managed, analyzed, and monitored with the help of spatial data to offer quicker, easier, and cost-effective solutions to the problem.

Modern advances in geospatial processing with the help of space-based synthetic aperture radar (SAR) sensors have enabled us to map and monitor flood-inundated areas. As such, these Sar datasets can infiltrate through the clouds to provide images in all weather conditions, including flooding conditions [14]. Real-time information extraction with SAR images helps in the identification of the flooded and flood-prone areas without physically visiting the affected areas to collect ground datasets. Apart from these, the augmented capability of cloud-based computing infrastructure enables wider access to large datasets for better management, storage capabilities, and speedy processing of datasets to generate results. In recent years, several researchers have used cloud-based computing platforms like google earth engine (GEE) for rapid satellite image processing over large areas to investigate the impacts of the flood on several other features including infrastructures and vegetations. Some of them have used the satellite-derived enhanced vegetation index (EVI) and normalized difference vegetation index (NDVI) for assessing the impact of floods on several vegetated features [15]. Therefore, it is always required to have accurate data on flood inundation to precisely assess the degree of damage in various aspects for feasible decision-making. The current work tries to assess the prospects of a cloud-based computing framework for geoprocessing and visualization of data in a distributed environment. It also attempts to ascertain the technology to facilitate the processing of large datasets like Sentinel-1A satellite datasets for detailed analysis with precise accuracy in the event of floods to estimate the extent of floods with instantaneous results at the time of emergency. It also intends to assess the results of satellitederived NDVI and EVI to further estimate the impacts of the floods on vegetation cover. Finally, the study attempts to deliver a valuable approach for informed decisionmaking in the event of flood mitigation planning for sustainable management of the resources. 


\section{Review of related literature}

There is an extensive body of literature on the use of remote sensing strategies to monitor and manage floods. Research has shown that advancements in science that leverage new techniques for receiving and processing data, as well as the use of software and information processing systems, play a major role in the management of limited water and soil resources [16]. Similarly, [17] recommended that the GIS model is one of the most useful methods for evaluating the intensity of soil erosion in the Delichai basin. The results were classified into low, average, and high-intensity erosion and were said to be less time-consuming and more cost-effective than other models. A study [18] used the Delphi technique to assess the intensity of floods in the Lvar watershed in Iran, utilizing six factors: rainfall, snow, slope, landform, land type, and vegetation. Based on the findings, the degree of flooding was categorized into five groups from very low to very high flooding. Researchers in a recent review publication [19] identified the areas highly potential for groundwater by extracting different geological features using ETM sensing imagery processing through class codes, edge detection filters, region classification, and their results were further verified using an error matrix. There have been a few studies that have looked at the effects of factors like inclination, rainfall intensity, and duration on runoff output. A similar study used a mathematical model to accurately anticipate the distinct stages of erosion and runoff to track the influence of these factors on soil loss and runoff production [20]. Another study used HEC_HMS software to investigate the possibility of prioritizing nine sub-basins in terms of flooding in the Eskandari catchment [21].

Flood extent delineation from RADAR or SAR images is primarily manual thresholding techniques, but it cannot cover multiple RADAR scenes to commonly tackle largescale areas. Moreover, they are considered to be computationally intensive when traditional remote sensing techniques are applied, which poses restrictions during emergencies [22]. Thus, the manual methods are often difficult, time-consuming, challenging, and produce less accurate results [23]. Different automated techniques and machine learning models have been developed to hasten the creation of inundation maps from RADAR or SAR images during the emergency of flooding events. Recent advancements in computational power, speed, storage, and cloud-processing platforms (e.g., google earth engine) enable a wide range of applications to take advantage of satellite image processing and analysis [24]. Several researchers have stated the various methods being applied to classify the water from the non-water pixels, including the supervised approach [25], unsupervised approach [26], visual inspection approach [27], time-series approach [28], threshold determination approach [29], support vector machine approach [30], neural network model approach [31], and other automated techniques. In recent years, artificial intelligence (AI) is being employed along with the Convolutional Neural Network (CNN) model consisting of three convolutional and max-pooling layers tailed by two fully connected layers for the different types of natural disasters to monitor disaster events [31]. Automatic detection of the features involves generative adversarial networks (GAN) and these are performed for flood detection [32].

It is commonly seen that water pixels return low backscatter values in comparison to non-water pixels [33]. However, an automatic threshold approach automatically detects the threshold values to separate water pixels from non-water pixels without the help of any training samples [29]. This method is considered one of the most rapid methods to attain binary classification of an image. The classification results are greatly influenced by determining the appropriate threshold values [34]. Several researchers have studied automatic thresholding approaches and reported that this technique can be used for flood monitoring [35]. It is often quoted in earlier research that the vegetation indices can be applied to the examination of crop responses to natural hazards like droughts and floods. Similarly, [36] utilized several vegetation indices to assess the flood damage in the United States. Di et al. [37] Suggested that all vegetation indices can detect the impacts of the flood on crops. The impacts of floods in the mid to late growing season can be analyzed with an estimation of the vegetation indices. Along with these, some researchers have attempted to utilize machine learning-based algorithms with a cloud-based computing platform to process, analyze, and map the flood-inundated areas for better assessment.

The massive plains of the Indian subcontinent are very prone to floods due to their specific geographical structures. The presence of the snow-clad Himalaya contains the largest glaciers that are the sources of various perennial rivers flowing in this range [38]. As per the reports of NIDM, the average rainfall of the Ganga plains is $1100 \mathrm{~mm}$. Due to heavy rains during the monsoons, water accumulates from various tributaries of the river carrying silts and sands deposits on the riverbeds. As a result, the pace of the river gradually reduces and starts bulging, expands horizontally, and submerges its surroundings, leading to excessive floods [39]. Furthermore, it disrupts the natural balance of fluvial, marine, and coastal ecosystems; large-scale erosion; changes in land forming processes; aggregate social problems like regional and state border disputes related to population displacement, ecological and economic failure, and reallocation [40]. 
During the year 2020, flood inundations occurred in the country along with the COVID-19 pandemics. The inadequate response to flooding has given rise to increased severity of the damage due to floods and spread the COVID-19 pandemic, which furthermore led to additional loss of life and property [41]. The latest approaches to respond to floods have helped a lot to the disaster management authorities to control and manage the impact of floods on several aspects. The cloud-based computing platform like google earth Engine (GEE) has enabled to facilitate the freely accessible platform for generating realtime immediate results for flood management. The vast amount of preloaded geospatial datasets along with parallel processing tools facilitates data downloading, processing, and storage capability [42]. The current work also performs a meta-analysis of the published research contributions from the Scopus database before the implementation of actual logic. This provides a comprehensive understanding of the published literature related to the google earth engine (GEE) computing platform. The significant research publications based on the 'Google Earth Engine (GEE)' keyword analyses the exhaustive list of publications with the statistics.

The attempted search query includes 'GEE and Floods and Surface Water Mapping' and 'GEE and Floods and Vegetation Indices' as shown in Table 1. This is followed by the keyword analysis based on the search queries where the most frequent terms are used. Some of the commonly used keywords are Google Earth Engine (GEE), Remote Sensing, Satellite Imageries, Surface Water Mapping, Flood Monitoring, Vegetation Indices, Normalized Difference Vegetation Index (NDVI), Enhanced Vegetation Index (EVI), Disasters, Environmental Monitoring, Cloud-Based Platforms, Algorithms, and Machine Learning. These are further analyses and reviewed based on the year and the countries involved in these publications. The search queries are executed for the research type including articles, conferences, and reviews published during 2017 and 2021 to showcase the latest advancement in the domain. The duplicate documents or articles are removed, and these are not selected further for the study. It is also observed that land-cover, classification, time-series, change detection, are the most used keywords and these are the most acknowledged applications of cloud-based GEE platforms.

The total number of research publications during 2017-2021 are plotted to visualize the relative comparison of two keywords including " floods and vegetation indices" and " floods and surface water mapping” (as shown in Table 1). The first category (i.e., floods and vegetation indices) is shown in blue colour and the other (i.e., floods and surface water mapping) is shown orange colour. It can be observed that the floods and surface water mapping keywords have fewer research documents in form of publications each year. A substantial increasing trend in the number of GEE publications is observed after the year (2017) as stated by the researcher [43] due to the increasing awareness among the developer community to comprehensively utilize the cloud-based platform for various remote sensing. The abovementioned analysis analyses the published research documents to provide an idea about the freshness of the study in the mentioned research domain. It is observed across the country that a very minimal amount of research has been accomplished with keywords like "floods and surface water mapping" and "floods and vegetation indices". Furthermore, the highest number of research publications for both keywords has been conducted by China and the United States, but there is still room for the Indian research community to perform research on the theme of Floods \& Vegetation Indices. India has very few research contributions in this field. The mentioned analysis provides a comprehensive trend to understand the recent updates in research for real-time applications.

\section{Materials and methods}

\subsection{Study area}

The current study is conducted for the region located between $21^{\circ} 95^{\prime} 01^{\prime \prime} \mathrm{N}$ to $27^{\circ} 31^{\prime} 15^{\prime \prime} \mathrm{N}$ and $83^{\circ} 19^{\prime} 50^{\prime \prime} \mathrm{E}$ to $89^{\circ} 50^{\prime} 00^{\prime \prime} \mathrm{E}$ as shown in Fig. 1. The area encloses the eastern part of the Indian subcontinent with a special focus on the states of Bihar, Jharkhand, and West Bengal. The region acts a the transitional belt which lies between the Himalayas (north) and the Deccan Plateau (south) [44]. The north part of the study area is surrounded by the Himalayan foothills and Terai region (Nepal) whereas the southern part of the region is covered by the Chotonagpur plateau.

The quaternary alluvium, which consists of sand, clay, and gravel, describes the lithology of this region. It is generally formed through the process of alluviation by the major river like Ganga along with its tributaries during the
Table 1 Summary of research documents in the Scopus database

\begin{tabular}{lcc}
\hline Search Queries & Total publications (Scopus Database) & publication year \\
\hline GEE and Floods and Surface Water Mapping & 29 & $2017-2021$ \\
GEE and Floods and Vegetation Indices & 135 & $2017-2021$
\end{tabular}




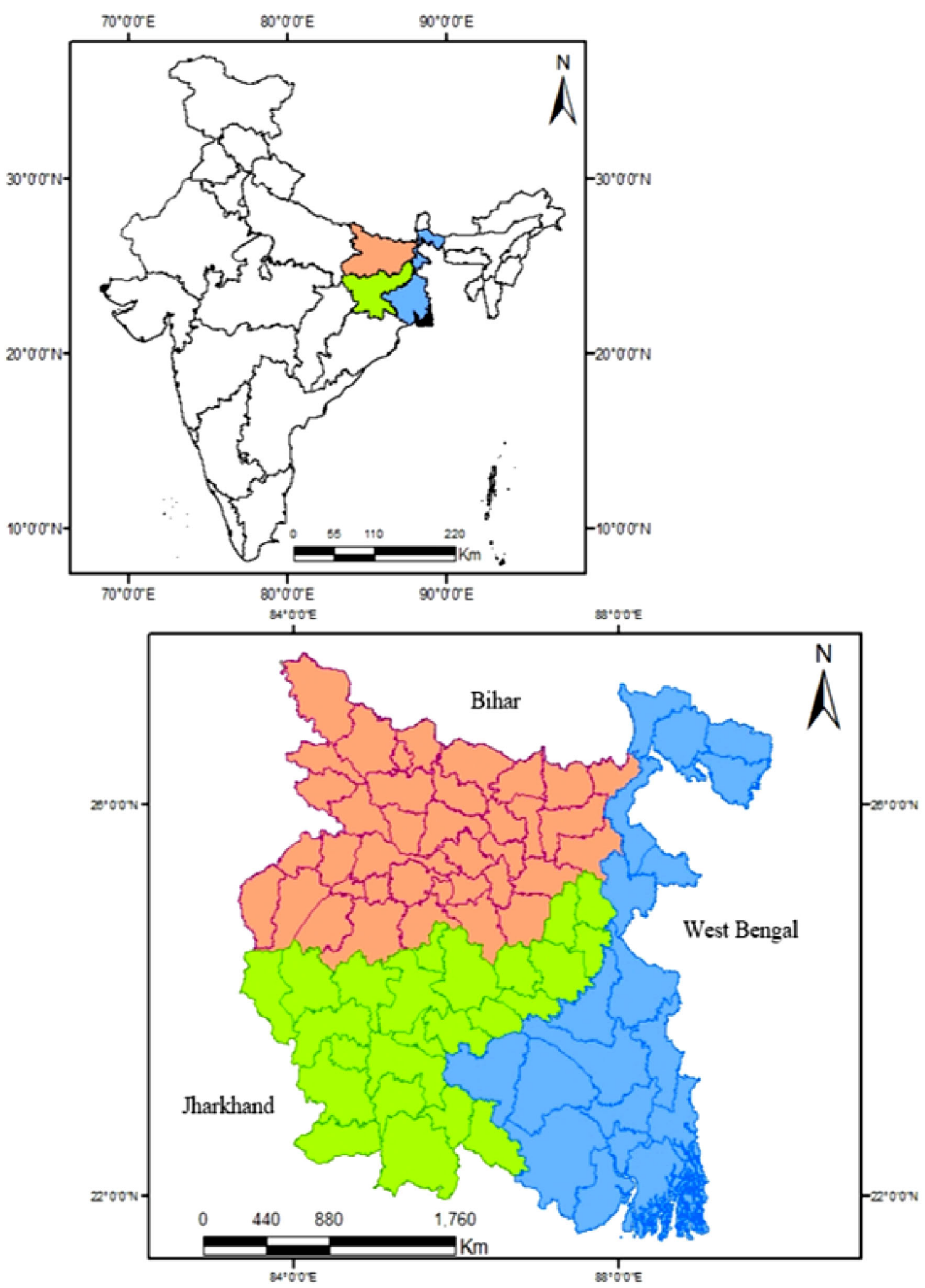

Fig. 1 Location map of the study area

late Tertiary and Quaternary periods. The natural vegetation of the region mostly comprises semi-deciduous forests and these are the home for several mammals and bird's species. The region comprises rich alluvial soils and these are brought down by the major river channels that are descending from the north. An extensive extends of 
alluvium is formed by the deposition of silt, which is brought down by numerous rivers and it makes the region one of the most appropriate lands for farming [45]. The flat plains and soil of the region make it more conducive for irrigation. There are major crops like rice, wheat, sugarcane, maize, cotton is grown in the region due to the presence of rich water resources. This also causes high population density in the plains of the region with agricultural practices as their major occupation with paddy as the main crop.

The Gangetic soil serves as the backbone of agricultural and industrial development for the large population residing in the region. In recent years, the gigantic Ganga plains are very much prone to floods, and flooding in the river mostly occurs during the monsoons [46]. The region is also affected by the southwest monsoon, and it contributes to about $80 \%$ of the total rainfall in the Indian sub-continent. A sufficient amount of monsoon rains mainly causes floods in the region and it causes overflow of the major rivers and their tributaries of the region. This results in the higher runoff from the upper basin during the monsoon period of July to August.

\subsection{Data and software used}

The present study mainly focuses on the states Bihar, West Bengal, and Jharkhand, and these are reported to be severely flooded and affected during the floods in July 2020. The study considers the pre-flood scenarios (i.e., from 15 April to 15 May 2020 and peak flood scenarios (i.e., 01 June to 30 July 2020). VH polarization of Sentinel$1 \mathrm{~A}$ images in descending direction is used to retrieve the required information related to floods. The land cover product of MODIS having a $500 \mathrm{~m}$ resolution is used to derive the influence of flood events. Similarly, the global surface-water dataset with a spatial resolution of $30 \mathrm{~m}$ is retrieved from JRC and the global human settlement population dataset with a spatial resolution of $250 \mathrm{~m}$ from the JRC is used to estimate the impacts of flood.

\subsection{Sentinel-1 SAR for flood hazard mapping}

The present study utilizes the multi-temporal Sentinel-1A images with a cloud-based computational platform like google earth engine (GEE). The Sentinel-1 SAR images of $\mathrm{C}$-band in-ground range detected (GRD) scenes of crosspolarized $(\mathrm{VH})$ signals in descending direction are used for pre-monsoon and peak-monsoon seasons to estimate the flood inundation. The pre-processing of the SAR images is performed through orbit file correction, radiometric calibration, thermal noise correction, and ortho-rectification techniques.
During the years, the Copernicus Earth Observation program from the European space agency (ESA) is facilitating free SAR datasets of the Sentinel-1 constellation (i.e., Sentinel-1A and Sentinel-1B), and these are very useful for flood hazard and responses studies. The flood hazard mapping with the help of SAR datasets is considered the most reliable method to quantify the extent of flood inundation over the region. The data from SAR sensors have the potential to penetrate through cloud cover, and it can operate in all weather conditions to provide near real-time information about flood inundations.

\subsection{Moderate resolution imaging spectro- radiometer (MODIS) for land cover}

Land use and land cover (LULC) datasets are used to provide useful information about the current landscape of the region. The information regarding agricultural fields, agricultural practices, ecosystems services, surface water bodies, forest cover along with their temporal dynamics is derived from the moderate resolution imaging spectro-radiometer (MODIS) datasets. The global land cover datasets for the study are generated with the help of MODIS-AQUA satellite observations. The required product of MCD12Q1 Version 6 is derived through the supervised classification of MODIS Terra and Aqua reflectance datasets. It provides global land cover types at yearly intervals (i.e. 2019 selected for this study) with a spatial resolution of $500 \mathrm{~m}$ with the six different classification schemes.

\subsection{Moderate resolution imaging spectroradiometer (MODIS) for vegetation indices}

The vegetation indices such as normalized difference vegetation index (NDVI) and enhanced vegetation index (EVI) are designed to estimate the temporal status of vegetation. NDVI estimates the density of green cover whereas EVI minimizes canopy background variations to maintain sensitivity over the dense vegetation cover. The moderate resolution imaging spectro-radiometer (MODIS) vegetation indices including NDVI and EVI are computed bi-directional atmospherically-corrected surface reflectance datasets, which are already masked for clouds, cloud shadows, aerosols, and water. The MYD13Q1.006 products are provided for every 16 days interval with a spatial resolution of $250 \mathrm{~m}$ as a gridded 3-level dataset used for this study. The datasets for the pre-monsoon (i.e., from 20 March to 10 June 2020) and peak monsoon (i.e., from 20 June to 30 August 2020) are acquired to generate the long term mean anomaly, and to create maps of vegetation changes, to report the graphical plots for further damage assessment and analysis caused due to the flood inundations. 


\subsection{Datasets used for damage assessment}

The global surface water dataset is developed by the European Commission's Joint Research Centre (JRC) of the Copernicus Programme. The global human settlement layer (GHSL) datasets of gridded population count are integrated with the flood inundation layer to assess the extent of the population affected by the flood inundations. The dataset with a spatial resolution of $250 \mathrm{~m}$ is supported by the joint research centre (JRC) facilitates several studies to extensively utilize the GPW datasets for mapping the impacts of disasters on the population. These products are generated from Landsat imagery maps for the permanent global distribution of water surfaces to provide the statistical changes over the extent of the water surfaces.

\subsection{Google earth engine (GEE)}

There are always certain restrictions associated with the monitoring of dynamic events like floods studies are limited to smaller extents due to limitations in the processing systems and the requirement of the separate computational system along with the software despite having high potentials of SAR datasets. But, over the years the advantages of freely accessible cloud-based cloud computational computing systems like google earth engine (GEE) enables us to process remote sensing datasets, especially in nearly-real-time scenarios and other dynamic events. GEE provides a cloud-based platform to facilitate the high-end processing of large-scale geospatial datasets processing. There is no such requirement of downloading the large volume datasets, storing of datasets, and fast processing due to the advancement of the new processing environment like GEE.

\section{Methodology}

The entire process for the present study is customized for the processing of datasets in the google earth engine (GEE) framework. Includes the detailed schematic for the SAR data processing and assessment of the flood inundated areas. The framework also describes the schematic for damage assessment for future studies and decision-making.

\subsection{Pre-processing of the datasets}

The preprocessing of datasets is required to delineate the flood hazard zones of the region to perform the detailed analysis with statistical computations in a cloud-based computational environment. The metadata properties are being used to create a homogeneous subset of Sentinel-1 data and thereafter necessary filter is also applied to enhance the quality of the datasets for further analysis. The radiometrically calibrated and terrain corrected Sentinel-1 SAR images available from the cloud-based computational framework of the GEE catalogue provide pre-processed required datasets, which are retrieved as per the approach.

\subsection{Backscatter intensity pattern}

The intensity of the backscatter pattern of processed microwave (SAR) datasets infers about the type of the features on the ground. The pixels with low grayscale intensity resemble water features whereas pixels with highintensity values resemble man-made or the non-water class (land). The water pixels in the processed SAR images are characterized by low backscatter due to the low backscatter response to the sensor and thereby most of the backscatter radar signals are not captured by the imaging sensors. The study analyses the backscatter response values for the SAR from the ground in pre-flood with $\mathrm{VH}$ polarization, and during the peak-flood scenarios in the $\mathrm{VH}$ polarizations. The backscatter intensity is measured in the $\mathrm{dB}$ (decibel) scale. Furthermore, it is required to observe the intensity values of the backscattered signals from the features during the pre-flood scenarios, during flood scenarios, and after the flood scenarios in the region.

\subsection{Surface water mapping}

The current study tries to attempt the surface water mapping strategies for the change detection due to the flooding event and monitoring of flood hazards regions and estimations of the inundated areas during the flooding event. Some of the researchers have attempted to utilize the change detection techniques and band ratio approaches with the help of multi-temporal SAR images for monitoring inundated areas, but this approaches lacks several aspects. To avoid the shortcoming of existing methods of flood inundation mapping, the current approach tries to eliminate the permanent water bodies with JRC global surface water datasets. The peak flood mosaic is divided by the pre-flood mosaic to estimate the outcome of the flooding event change on a per-pixel basis. Bright values indicate a high level of change whereas the dark values show a low level of change in the raster image. The threshold operator is used to extract the bright pixels from the raster image. With a trial-and-error approach, an optimal threshold is selected, and thereafter a raster layer is created through the binary image where the threshold of 1.15 is considered to estimate the flood hazard. The superimposition of the classified binary image is created where the pixels having values greater than the threshold limit are considered as flooded pixels and the pixels with values less than the threshold limit represents a non- 
flooded pixel. The method is used to observe the changes depending on the time selected for comparison.

\subsection{Enhancement of flood hazard layer}

The estimated flood inundated layer obtained from the processing chain is further refined/enhanced by eliminating the permanent water features from the region. It is performed with the help of the JRC global surface-water dataset of (2018, $30 \mathrm{~m}$ resolution) to mask the areas covered with permanent water for more than 10 months in the year. These datasets are further processed for the estimation of areas under flood hazard and damage assessment. Table 2 reports the status of the land use and land cover (LULC) in the region and the total area under different LULC is reported as total area (in $\mathrm{km}^{2}$ ).

\subsection{Vegetation indices analysis}

The normalized difference vegetation index (NDVI) is considered as one of the most efficient, accurately measured, widely utilized global vegetation indices. It is furthermore commonly associated with several biophysical properties like the vegetation cover, canopy, biomass, leaf area index, and change analysis. Thus, NDVI is termed as a vegetation proxy due to the vegetation characteristics provided by the index [47]. The formula for NDVI is stated in Eq. (1) where $\rho_{N I R}, \rho_{R e d}$ denotes the surface reflectance for the MODIS bands averaged over the defined near-infrared (NIR) and red sections of the electromagnetic spectrum.

$N D V I=\frac{\rho_{N I R}-\rho_{\text {Red }}}{\rho_{\text {NIR }}+\rho_{\text {Red }}}$

The study also utilizes another index like enhanced vegetation index (EVI) derived from the MODIS dataset and it is enhanced to optimize the vegetation signal by de-coupling of the canopy background signal [47]. The equation for EVI is well presented in Eq. (2), where G is denoted as the gain factor $(\mathrm{G}=2.5)$, $\mathrm{L}$ represented the canopy background adjustment $(\mathrm{L}=1), \mathrm{C}_{1}$ and $\mathrm{C}_{2}$ symbolized aerosol coefficient that used a blue band of MODIS to remove the presence of aerosol influence on a red band of MODIS $\left(\mathrm{C}_{1}=6\right.$ and $\left.\mathrm{C}_{2}=7.5\right)$, and $\rho_{\text {NIR }}, \rho_{\text {Red }}, \rho_{\text {Blue }}$ are the surface reflectance for the red, blue, and near-infrared bands respectively [42].
$E V I=G\left\{\frac{\left(\rho_{\text {NIR }}-\rho_{\text {red }}\right)}{\left[\rho_{\text {NIR }}+C_{1}\left(\rho_{\text {red }}\right)-C_{1}\left(\rho_{\text {blue }}\right)+L\right]}\right\}$

The estimation of the vegetation indices and the entire data analysis is performed with the help of google earth engine (GEE). The MODIS-derived NDVI and EVI images are retrieved from the GEE library and afterwards required image processing and analysis are performed for the selected region and for the selected timeframe (i.e. preflood and post-flood scenarios). The spatial and temporal variation of the vegetation indices is analyzed with the averaging approach. To analyze the changes of the NDVI and EVI for pre-monsoon and post-monsoon, a mean value of the NDVI and EVI across all pixels for the selected periods is estimated. The anomalies in the values of NDVI and EVI estimates are used to understand the impact of the flood during the mentioned season on an average scale.

\subsection{Assessment of flood hazard layer}

After completing the required steps, it is essential to assess the authenticity of the results, and the same is accomplished with help of several other additional datasets. The MODIS datasets are reclassified into 6 categories and corresponding statistical estimations of the area under the major LULC categories (i.e., total cropland area and total settlement area in the $\mathrm{km}^{2}$ ) are presented in Table 2. This is resampled with the flood inundation extend the map to extract the cropland and built-up affected areas due to the flooding event. Additionally, The GHSL dataset is also analyzed to estimate the number of exposed persons under the flood per pixel. Both layers are overlapped to generate another raster layer to estimate the affected population. Moreover, the estimated flood inundation areas are also validated with the published reports from various opensource about the affected flood zones.

Thereafter, an accuracy assessment with visual, digital, and statistical precision is performed for the flood inundation map and the vegetation indices. The visual accuracy compares the random sites of the classified images regarding the actual sites as seen against the google earth historical images. The statistical accuracy is estimated with the analysis of the confusion matrix including measures like overall accuracy, kappa coefficient, producers, and user's accuracies. The total number of correctly classified pixels is estimated for the overall accuracy of the classification algorithm. The kappa coefficient measures the
Table 2 Area under major LULC categories

\begin{tabular}{lcccc}
\hline LULC categories area & Jharkhand & Bihar & West Bengal & Total area $\left(\mathrm{km}^{2}\right)$ \\
\hline Total Cropland Area $\left(\mathrm{km}^{2}\right)$ & 70,624 & $1,10,213$ & 89,261 & $\mathbf{2 , 7 0 , 0 9 8}$ \\
Total Settlement Area $\left(\mathrm{km}^{2}\right)$ & 1032 & 1797 & 2675 & $\mathbf{5 5 0 4}$ \\
\hline
\end{tabular}


overall accuracy compared with the assigned values. The higher order of the kappa coefficient values infers the higher accuracy of the classified images. The current focus towards the performance of the mentioned workflow to analyze the flood detection, hence the producer and the user accuracies are also performed for classified images as well for the validation of the vegetation indices.

\section{Results and discussion}

\subsection{Spatio-temporal variation analysis and area under flood inundation assessment}

The study demonstrates that a large area of $16,220.95 \mathrm{~km}^{2}$ was affected due to the floods from 30 June to 20 July 2020. The flood inundation significantly affects the lower Ganga basin including the parts of India and Bangladesh. It is observed that the region of Bihar is battling on two fronts including the COVID-19 and flood. Most of the districts in north Bihar are involved with fishing and farming and these communities are the worst affected in the region. This affected widespread loss of livelihood to people, marooned settlements, displaced families to temporary shelters, washed away standing crops, food insecurity, non-accessibility of basic needs, improper sanitation, and these caused severe violations of COVID-9 pandemic guidelines for the spread of the disease [48].

The datasets derived from the cloud-based computational platform are reclassified into six major classes including forests, grassland, cropland, urban, water bodies, and others. Table 3 reports that exhibits the detailed area and population affected due to the flood over the different states. The LULC maps show that the northern part of Bihar, central and northern part of West Bengal is severely affected due to the flood in July 2020. Figure 2 shows the MODIS derived LULC map (a) water coverage before flood occurrence and (b) scenario during the peak flood caused by heavy rainfall.

\subsection{Change analysis of LULC classes and population}

Figure 3 visualizes the flood-affected regions of the different land use and land cover classes. The first Fig. 3a shows the crop coverage (as shown in yellow colour) and the affected cropland is shown with the orange colour in the same image, which mostly covers the parts of Bihar and West Bengal, with rarely affecting the state of Jharkhand. The statistical analysis is shown in graphical form displays the percentage change of the areas in the corresponding LULC categories due to the occurrence of these floods. The second Fig. $3 \mathrm{~b}$ presents the number of marooned populations (persons per pixel), white pixels represent the nonexposed population to flood and red represents the suffered or affected population. The statistical representation of the cumulative inundated area of the different states considered for the study. The figure delineates that the state of Bihar is having more impacts of flood mostly due to the monsoon rainfall. In comparison to this, Jharkhand is the least affected. It can be observed that the devastating floods affect the state of Bihar with an area of $8863.31 \mathrm{~km}^{2}$, West Bengal with an area of $7072.64 \mathrm{~km}^{2}$ whereas it affects the state of Jharkhand with an area of $285.0 \mathrm{~km}^{2}$. The state of Jharkhand is comparatively less affected due to the flooding event. The inundated areas are mainly surrounded by major rivers (Ganga and Kosi) and these are responsible for the frequent flooding event during the monsoon seasons. It is also seen that during the peak flooding scenario, the presence of moderately small inundated discrete areas along with the settlements is getting affected. The same is analyzed with the help of statistical analysis and the corresponding results.

\subsection{Spatio-temporal trends of vegetation cover due to the flooding event}

The vegetation indices namely NDVI and EVI values are estimated for the pre-flood and the peak-flood period to monitor the vegetation changes induced due to the flooding event. The results are obtained from the analysis MODIS product to visualize the trends of NDVI and EVI for both

Table 3 Impact of flood inundation

\begin{tabular}{lllll}
\hline Impact/area affected & Jharkhand & Bihar & West Bengal & Total \\
\hline Area under flood inundation & $285.06 \mathrm{~km}^{2}$ & $8863.31 \mathrm{~km}^{2}$ & $7072.64 \mathrm{~km}^{2}$ & $16,220.95 \mathrm{~km}^{2}$ \\
The area under cropland affected by flood & $670.92 \mathrm{~km}^{2}$ & $4217.61 \mathrm{~km}^{2}$ & $3972.11 \mathrm{~km}^{2}$ & $8860.64 \mathrm{~km}^{2}$ \\
The area under settlement affected by flood $\left(\mathrm{km}^{2}\right)$ & $1.23 \mathrm{~km}^{2}$ & $205.03 \mathrm{~km}^{2}$ & $529.12 \mathrm{~km}^{2}$ & $735.38 \mathrm{~km}^{2}$ \\
Total population affected by flood (persons) & 99,873 & $4,403,258$ & 743,359 & $5,246,490$ \\
\hline
\end{tabular}



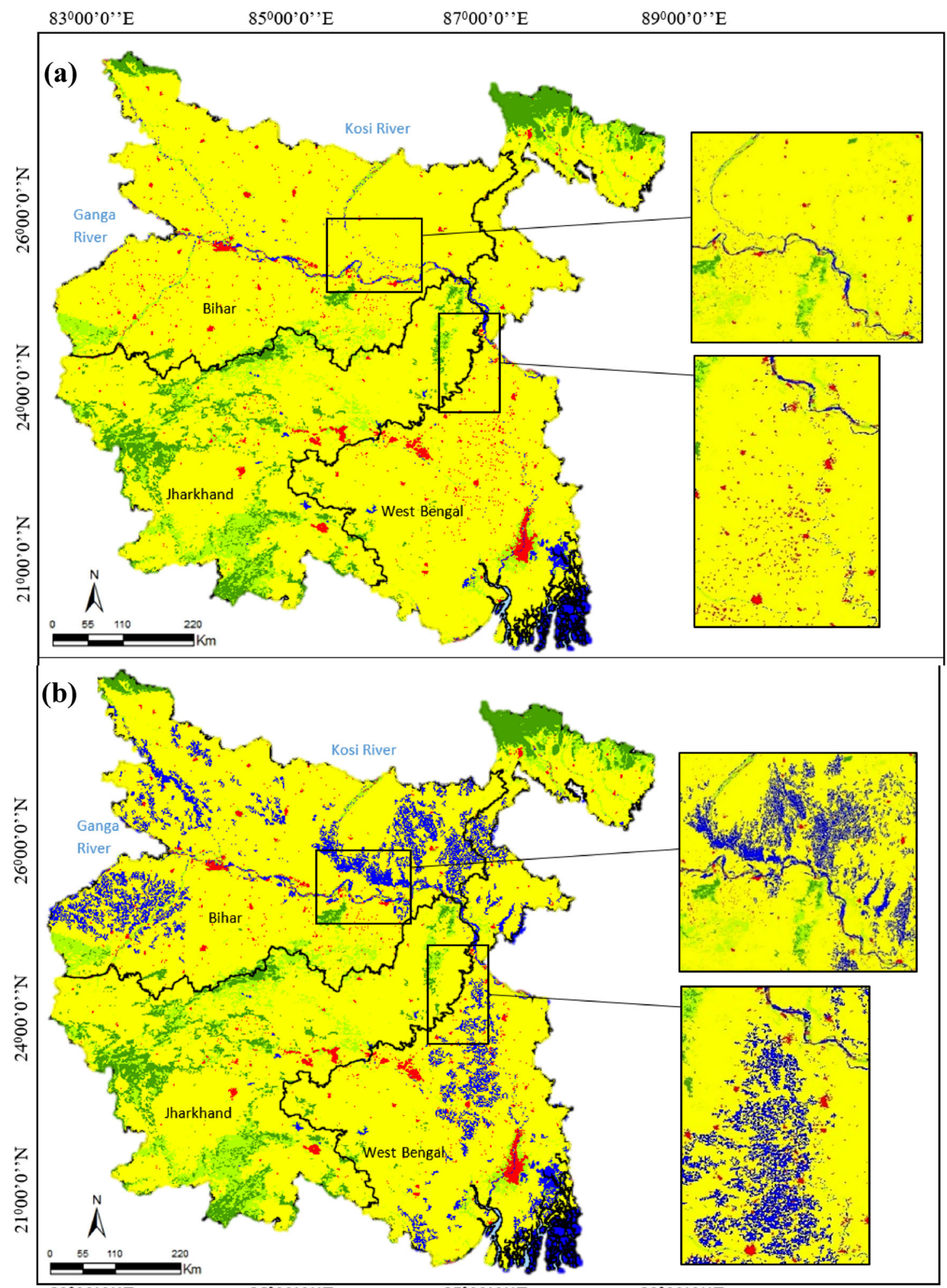

$83^{\circ} 00^{\prime} 0$ '' $\quad 85^{\circ} 00^{\prime} 0$ '’ $\mathrm{E} \quad 87^{0} 00^{\prime} 0$ '’ $\mathrm{E}$

$89^{\circ} 00^{\prime} 0^{\prime \prime} \mathrm{E}$

Forests $\square$ Grassland

Cropland

Water-bodies

Urban

Others

Flood Inundation

$\square$ State Boundary

Fig. 2 MODIS derived LULC maps a pre-flood scenario, b Flood inundation during peak flood 
Fig. 3 Results of flood impacts a Effect on agricultural cropland with MODIS LULC dataset, b Effect on the population (persons per pixel) with the GHSL datasets
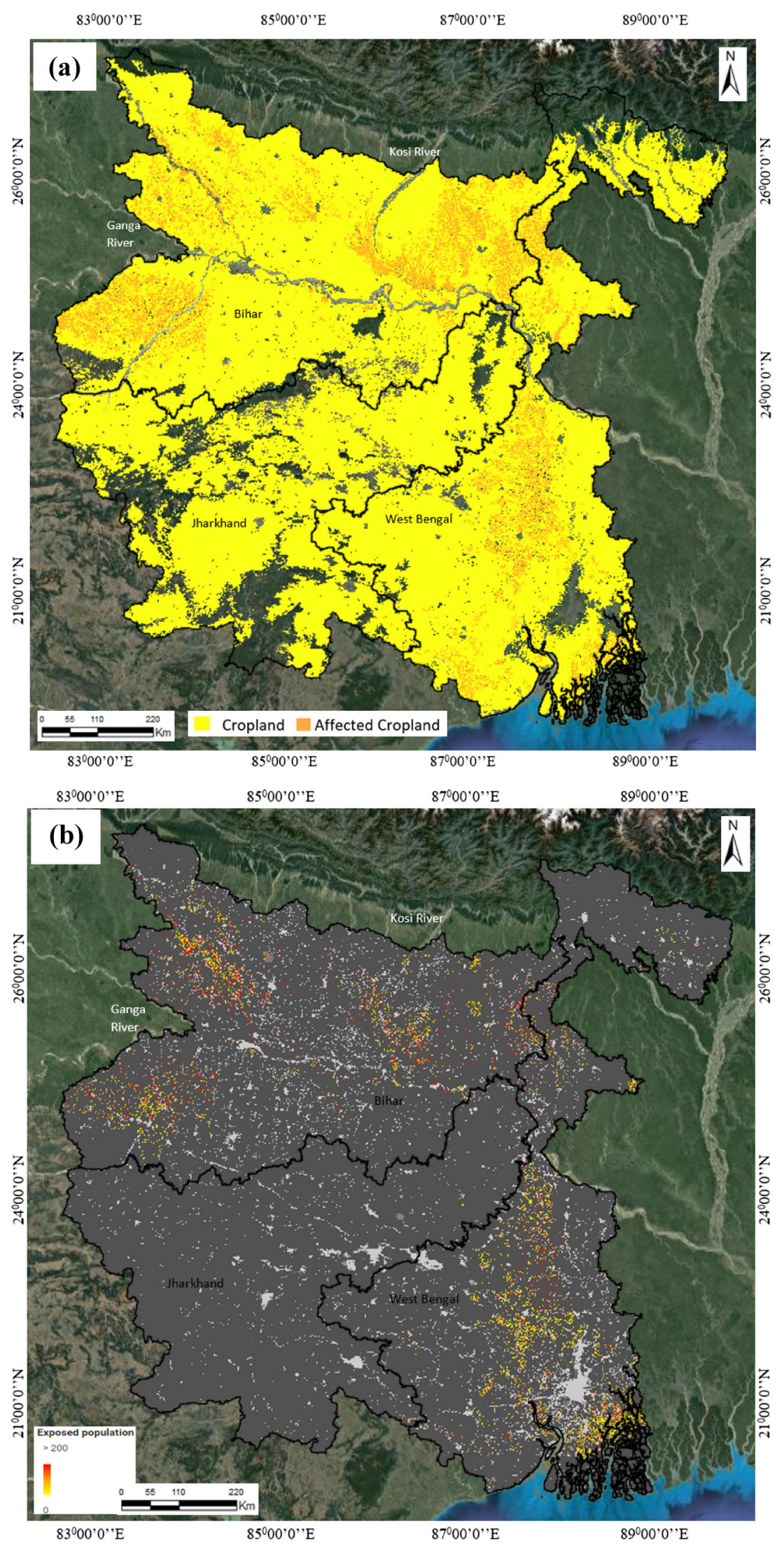
periods. The temporal change pattern of NDVI and EVI is shown in Fig. 5 to understand the variation of the index's values. The corresponding values of the indices show the fluctuating trends over the mentioned period. The values of NDVI and EVI indices during the peak monsoon are observed to be lower. The data points for both indices are selected for the year 2020 during the month FebruarySeptember. It is observed that the maximum value of NDVI is 0.66 with a minimum value of 0.26 , and this occurs due to the floods in the region. In addition to this, a similar fluctuation trend is observed for the case of EVI indices with a maximum value of 0.43 and a minimum value of 0.17 in July. It can be seen that the values of NDVI and EVI have the highest peak in September, whereas it shows a dip in the values in July due to the occurrence of heavy floods. On the other hand, the trend plot indicates that the normalized difference vegetation index (NDVI) values are higher in compared to the range of Enhanced vegetation index (EVI) values and there is a dip in the trends during the peak monsoon season which again rises from September and this common for both the indices. The NDVI and EVI values are mostly below normal after the event till August 2020, as shown in Table 3.

To understand the condition of floods in a more detailed manner, three sub-regions are selected and named as (a, b, and c) and these are spatially located at distance apart from each other to demonstrate the variations of the vegetation indices to compare the results. The precise locational extent of each location for three sub-regions is shown with the blue rectangular boundary in the reference map shown in Fig. 4. The values of vegetation indices ranged between -1.0 to +1.0 where the negative values indicated the absence of water whereas the positive values imply the correlated green vegetation. The range of NDVI and EVI are higher for the pre-monsoon months (February-June) as shown in Fig. 4 and the trends are common for all the three sub-regions. Unlike the pre-monsoon period, the vegetation indices at the time of heavy monsoon show a steep fall in the values and this is stated in the figures of NDVI and EVI (Figs. 4 and 5) for July to mid of August. It is also seen that the majority of the EVI and NDVI anomaly values in the affected areas observed lower values than normal whereas those regions away from the affected areas observed little or no change. It is found that the results are valid in outlining the patches where severe damage is observed when compared with the NDVI and EVI anomaly figures. The averaging of the spatial mean distribution of NDVI values are shown in Fig. 5 and the spatial distribution of EVI values is shown in Fig. 5. The change in indices values at the pixel level is shown to identify the impact of the flood on the vegetation cover. It is observed that the median values of EVI along the river basin vary within the range of $0.15-0.35$ all through the selected time frame. Among the three sub-location, location (A) has a larger number of red pixels coving most parts of the area, which signifies that the area is mostly affected due to the floods and it reflects the major changes in the values. The figures with NDVI and EVI anomalies clearly show that the trends of flood occurrence in the region. This implies that the region experiences an obvious vegetation change after the occurrence of the flood event.

The overall accuracy obtained for the flood inundated map is about $89.5 \%$ with a kappa coefficient of 0.79 . Table 4 presents the accuracies of the results obtained from the confusion matrix. The results show a fair recognition of the inundated areas with fair validation of results with the help of google earth images. The obtained results are validated on a large scale for rapid flood inundation mapping with the google earth historical archive for the selected dates. Similarly, the overall accuracy for EVI and NDVI is observed with change anomalies of $90.2 \%$ for NDVI and $87.8 \%$ for EVI with a kappa coefficient of 0.88 and 0.81 representing reasonable agreement. A confusion matrix is generated for accuracy assessment. The overall accuracy of the flood inundation map is observed as $89.50 \%$ with the kappa coefficient of 0.79 . The method achieves a producer's accuracy of $88.10 \%$ with a user's accuracy of $89.21 \%$.

The obtained results of this study describe that the total area under the flood inundation is approximately $16,220.95 \mathrm{~km}^{2}$ and the maximum inundation is estimated for the state of Bihar with $7.25 \%$ of the total geographical area, West Bengal is affected with around $6.48 \%$ whereas Jharkhand is affected with $0.27 \%$. In-state of Bihar, the most affected districts include Darbhanga, Muzaffarpur, West Champaran, Saran, and Siwan.

Most of the farming and fishing communities' homes and cattle sheds are completely submerged. The results display the total cropland affected area is approximately $8860.64 \mathrm{~km}^{2}$ and the total settlements affected area is $735.38 \mathrm{~km}^{2}$. It is also observed that most of the cropland and settlement areas are affected mostly in the states of Bihar with cropland as $3.83 \%$ and settlement as $11.35 \%$; in West Bengal is effected with a cropland area of $4.45 \%$ and settlement area of 19.78\%); in Jharkhand, cropland is effected with $0.95 \%$ and settlement is effected with $0.12 \%$. The global human settlement population data shows that a large population comprising a population of 5,246,490 people are affected in the entire region due to the flood of July 2020. This is followed by Bihar (4,403,258 people), West Bengal (743,359 people), and Jharkhand (99,873 people) as shown in Fig. 4. NDVI and EVI indices are widely used for change detection analysis. The present study analyses the impact of floods on vegetation. The results show that the vegetation indices (NDVI and EVI) are substantial in detecting the changes within the surface 
features of the large visible area. The NDVI and EVI indices are highly correlated with the seasonal trends during the peak monsoons. The lowest values of NDVI and EVI indices are observed in July, and these are due to the rise of floodwater. It affects the vegetation cover across the river channels like Ganga and its tributaries. It is clear from the results that the maximum hazards are observed near the rivers which are also assumed to be most vulnerable to flood risk. The evidence obtained from this research can be considered for the immediate response and rehabilitation during the flooding events. Moreover, at times when there is country-wide lockdown and life in parts of Bihar and West Bengal came to standstill due to the floods.

As social distancing becomes a new norm in the COVID-19 outbreak, the only solution to observe floods in real-time scenarios lies with remote sensing to provide detailed information. The development of advanced algorithms with the integration of the datasets provides scope for coping with the dual calamity. Distribution teams can provide aids to people in the shelter with the help of this

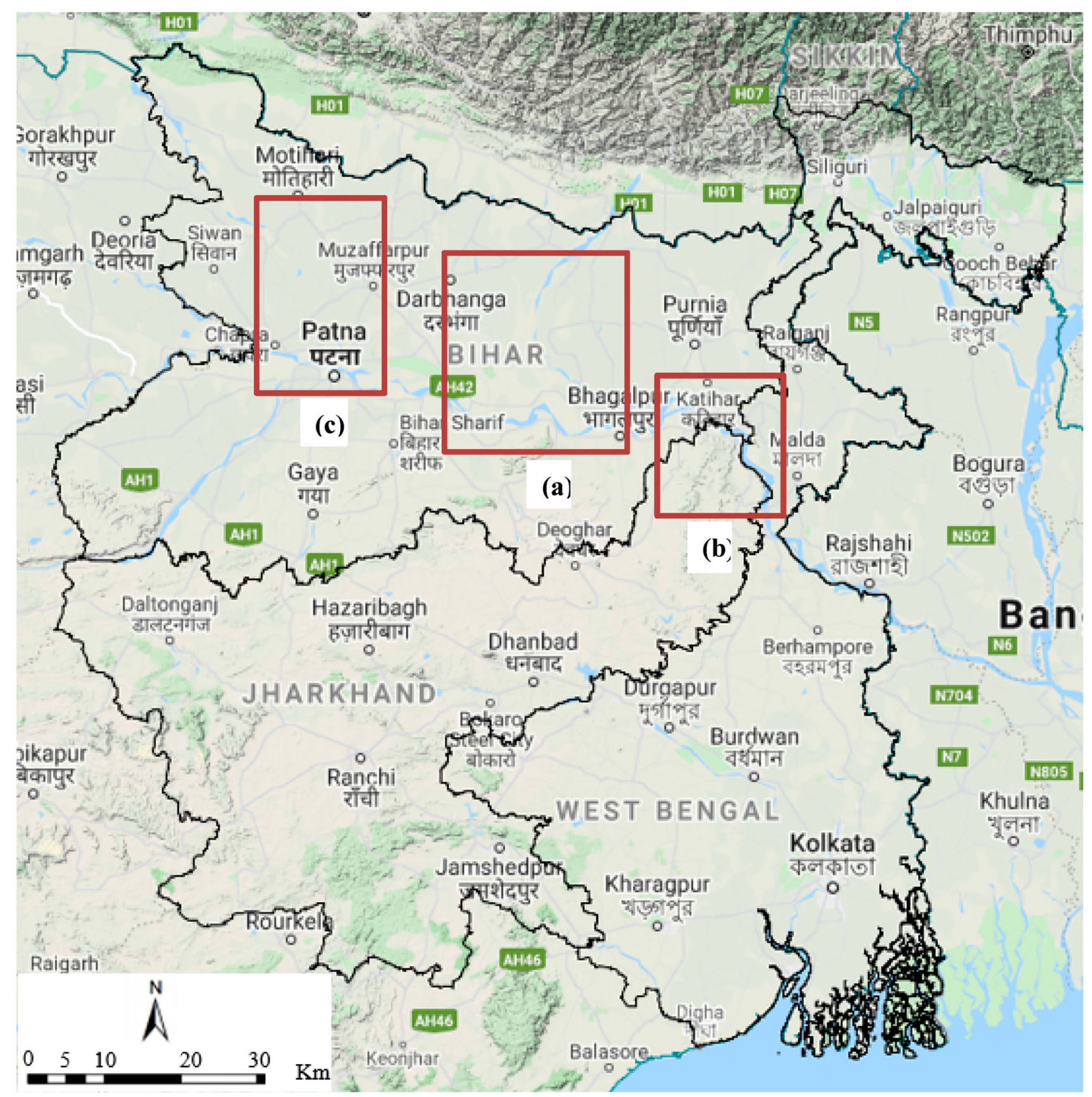

Fig. 4 Vegetation indices estimation for selected sub-regions in study area. a Pre-flood (NDVI) b Peak-flood (NDVI) c Change (NDVI) 

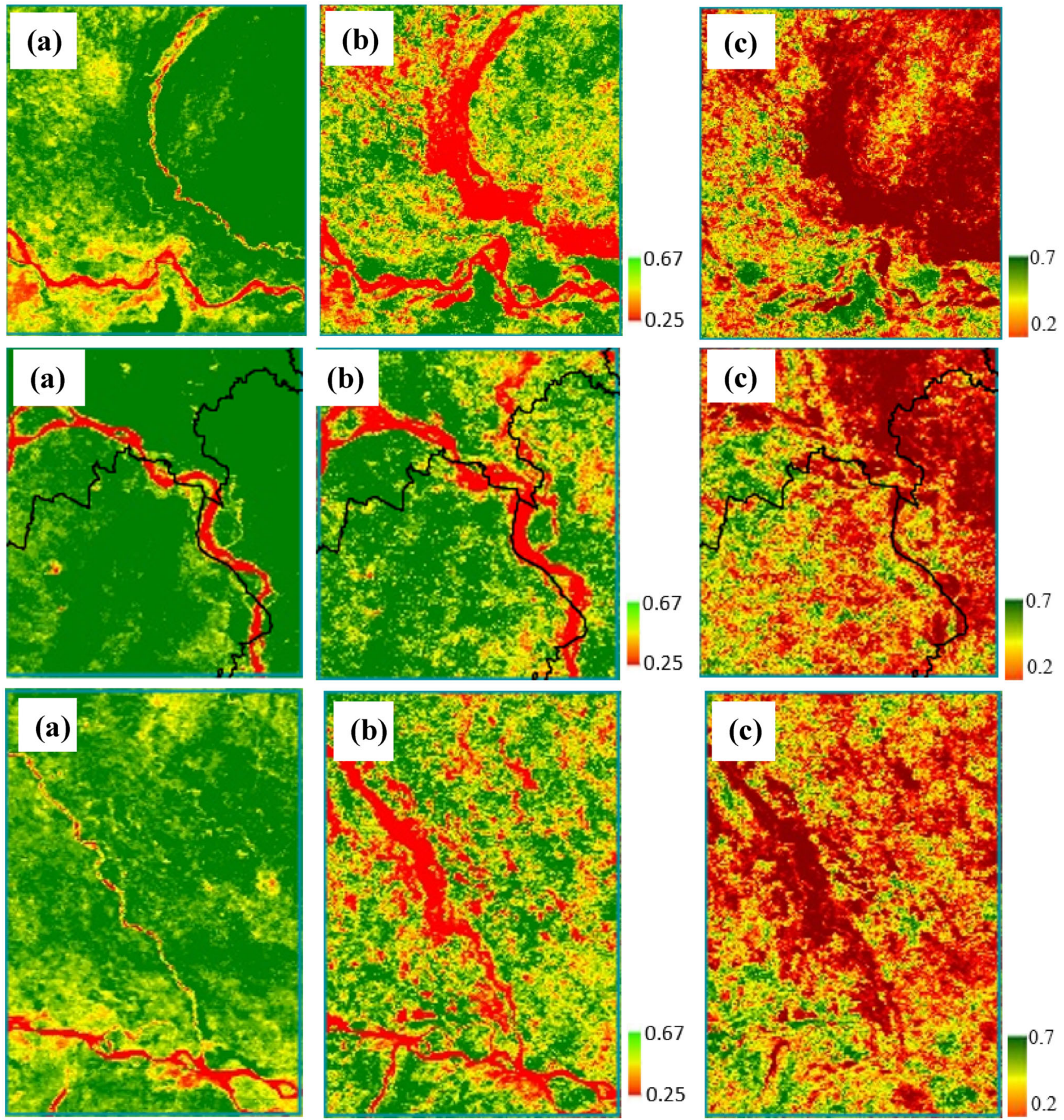

Fig. 4 continued

real-time information. It is a challenging task to manage such a huge population and shift them to relief camps at the time of the COVID-19 period [49]. According to the official reports, the pandemic not only disrupted the normal lifestyle in Bihar but also hit several flood controls projects. Several embankment repair as well as maintenance projects have come to a standstill in the state due to COVID-19 fears [50]. It is reported that amid the rise in the spread of the COVID-19 pandemic, thousands of people are forced to relocate as more than a hundred villages are affected by the floodwaters. The official data of the State Disaster Management Department (Bihar) stated that 156 panchayats in 32 blocks in districts of Sheohar, Sitamarhi, Kishanganj, Muzaffarpur, Gopalganj, Khagaria, and Darbhanga in Bihar are severely affected by the floods [51]. In this study, the backscatter values for pre-flood with 

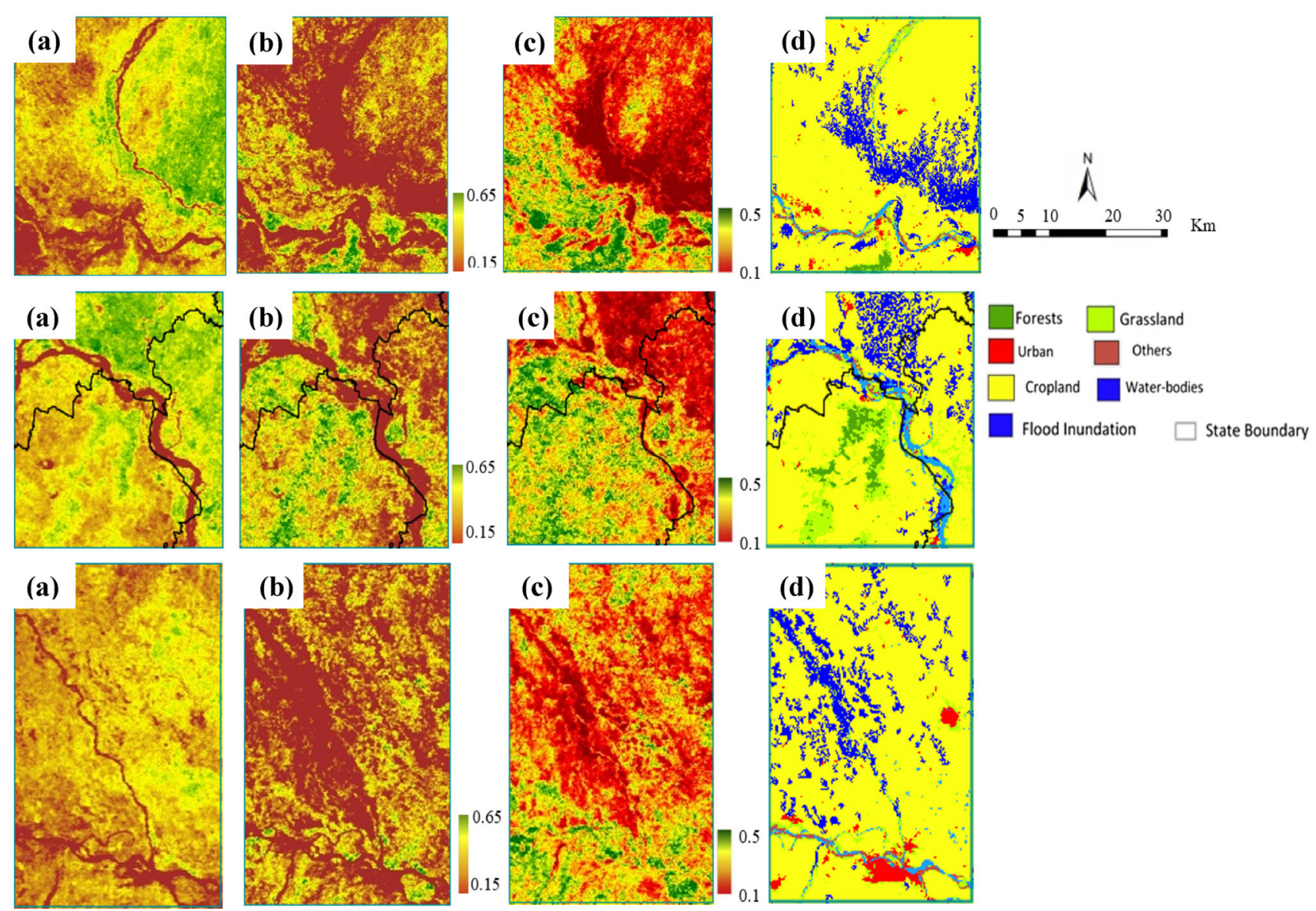

Fig. 5 Enhanced vegetation index (EVI) outcomes over the selected sub-regions. a Pre-flood (EVI) b Pre-flood (EVI) c Change (EVI) d Flood Inundation (EVI)

Table 4 Accuracy assessment of results obtained (EVI and NDVI)

\begin{tabular}{lllll}
\hline Accuracy assessment & Kappa coefficient & Producer's accuracy & User's accuracy & Overall accuracy \\
\hline Inundation map & 0.79 & 88.1 & 89.29 & 89.5 \\
NDVI Change map & 0.88 & 91.0 & 90.6 & 90.2 \\
EVI Change map & 0.81 & 85.3 & 89.6 & 87.8 \\
\hline
\end{tabular}

$\mathrm{VH}$ polarization are between $(-7$ to -15$) \mathrm{dB}$, and during the peak-flood was between $(-23$ to -28$) \mathrm{dB}$. Furthermore, it is observed that the backscatter intensity values decreased for the peak flood due to heavy flooding in those areas.

It is evident from the results that the threshold method on Sentinel-1 SAR image can precisely differentiate between the water and non-water pixels, and these can be useful in detecting the inundated areas. Sentinel-1 SAR and MODIS datasets play a significant role in producing largescale robust flood risk maps to analyze the impacts of floods. The LULC results obtained are highly computationally efficient on the cloud-based platform. The algorithm for the calculation of the indices has performed well on the GEE platform. Not only for the MODIS datasets but the practical algorithm can also be easily extended to other satellite datasets like Sentinel or Landsat. Compared with previous studies, the MODIS-derived NDVI and EVI results are advantageous for studying the pattern of vegetation after a flood occurs, as that can give more insight into the damage.

This paper has developed a new technique to delineate the effects of flooding along with the severe damage over a large area using a cloud-based platform. However, one of the major limitations of this study is that the field data collection was not feasible due to the occurrence of compound hazards, so the real-time data helped analyze the effects. The results provide a fundamental measure for flood risk management to provide an immediate response 
on urgent issues, with a focus on the emergencies, and the resource shortages in the affected regions.

\section{Conclusion}

The current study analyzes the recent flood of July 2020, with a special focus on the states of Bihar and West Bengal. It is observed that the flood disrupted a huge population with damage to life and property. The work emphasizes the significance of the cloud-based computation framework during the COVID-19 pandemic situation. The estimated accuracy of the inundated map-derived maps with the mentioned approach is comparable with an accuracy of $89.50 \%$ and it justifies the method for flood monitoring with precise accuracy. Similarly, the NDVI change anomalies surpass the EVI transformation. The current highlights the affected areas of cropland and settlements. Moreover, flood risk mapping is substantial for the development of, low-cost solutions with cost-effective and robust techniques. The fusion of high-resolution multisensor datasets improves the precision of flood detection and damage assessment approaches with more enhanced real-time flood information mapping. The assessment of vegetation indices after the flood event shows a prospect to generate large-scale vegetation distribution maps along with the instant evaluation of the damaged areas with the use of the MODIS-derived EVI and NDVI indices. The assessment of pre-and post-flooding scenarios in future studies can be performed with satellite-based datasets along with in-situ values. Some other indices can be explored with a comparative analysis with the analogous indices to analyze the optimal indices. The approach can also be applied to other water-induced disasters including droughts, tsunamis, and landslides. The obtained results are validated with the available datasets, and it is observed that the cloud-based Google Earth Engine (GEE) platform are beneficial for instant processing of the datasets. The obtained results on a nearly real-time basis will provide a precise solution for further studies.

Acknowledgements We thank and gratefully acknowledge NASA (National Aeronautics and Space Administration, United States) and U.S. Geological Survey for providing Landsat satellite data. We are thankful to the Copernicus Sentinel data policy for the free, full, and open data policy adopted for the Copernicus program foresees access to all users. This work was undertaken as part of a full-time PhD program. All the authors fully acknowledge the Google Earth Engine platform for providing a planetary-scale geospatial analysis portal.

Author contributions Dr Deepak Kumar conceived and designed the study, and Ms Sukanya Ghosh performed the research, analyzed the data, and Dr Deepak Kumar along with Dr Rina Kumari contributed to data analysis and editorial input.

\section{Declarations}

Conflicts of interest The authors declare that there is no conflict of interest regarding the publication of this paper.

\section{References}

1. Lal, P., Kumar, A., Kumar, S., Kumari, S., Saikia, P., Dayanandan, A., Adhikari, D., \& Khan, M. L. (2020). The dark cloud with a silver lining: Assessing the impact of the SARS COVID-19 pandemic on the global environment. Science of The Total Environment. https://doi.org/10.1016/J.SCITOTENV.2020. 139297

2. Alhassan, S. I., Akoto, J. D., Ackah, M., Mintah, S., Zhao, F., \& Wang, H. (2020). Assessing the impacts of COVID-19 pandemic on the environment: A correlation or causation? Global Journal of Ecology. https://doi.org/10.17352/GJE.000027

3. Yunus, A. P., Masago, Y., \& Hijioka, Y. (2020). COVID-19 and surface water quality: Improved lake water quality during the lockdown. Science of the Total Environment, 731, 139012. https://doi.org/10.1016/J.SCITOTENV.2020.139012

4. Aswathy, T. S., Achu, A. L., Francis, S., Gopinath, G., Joseph, S., Surendran, U., \& Sunil, P. S. (2021). Assessment of water quality in a tropical ramsar wetland of southern India in the wake of COVID-19. Remote Sensing Applications: Society and Environment, 23, 100604. https://doi.org/10.1016/J.RSASE.2021.100604

5. Muduli, P. R., Kumar, A., Kanuri, V. V., Mishra, D. R., Acharya, P., Saha, R., Biswas, M. K., Vidyarthi, A. K., \& Sudhakar, A. (2021). Water quality assessment of the Ganges River during COVID-19 lockdown. International Journal of Environmental Science and Technology, 18(6), 1645-1652. https://doi.org/10. 1007/s13762-021-03245-x

6. Garg, V., Aggarwal, S. P., \& Chauhan, P. (2020). "Changes in turbidity along Ganga River using Sentinel-2 satellite data during lockdown associated with COVID-19. Geomatics, Natural Hazards and Risk, 11(1), 1175-1195. https://doi.org/10.1080/ 19475705.2020.1782482

7. Waters, C., Mishra, D. R., Kumar, A., Muduli, P. R., \& Equeenuddin, S. (2020). Decline in phytoplankton biomass along indian coastal waters due to COVID-19 lockdown. No. Figure 1.

8. Phillips et al. (2020). Compound climate risks in the COVID-19 pandemic-Pesquisa Google.

9. Ray, K., Pandey, P., Pandey, C., Dimri, A. P., \& Kishore, K. (2019). On the recent floods in India. Current Science, 117(2), 204-218. https://doi.org/10.18520/CS/V117/I2/204-218

10. Patwardhan, A. (2007). Paper 10 disaster prevention, preparedness and management and linkages with climate change adaptation.

11. Tripathy, S. S., Bhatia, U., Mohanty, M., Karmakar, S., \& Ghosh, S. (2021). Flood evacuation during pandemic: A multi-objective framework to handle compound hazard. Environmental Research Letters. https://doi.org/10.1088/1748-9326/abda70

12. Ishiwatari, M., Koike, T., Hiroki, K., Toda, T., \& Katsube, T. (2020). Managing disasters amid COVID-19 pandemic: Approaches of response to flood disasters. Progress in Disaster Science, 6, 100096. https://doi.org/10.1016/J.PDISAS.2020. 100096

13. Daily Flood Situation Report cum Advisories I Flood Management Organisation. Central Water Commission, 2020.

14. Lattari, F., Leon, B. G., Asaro, F., Rucci, A., Prati, C., \& Matteucci, M. (2019). Deep learning for SAR image despeckling. Remote Sensing, 11(13), 1-20. https://doi.org/10.3390/ rs11131532 
15. Kwak, Y., Arifuzzanman, B., Iwami, Y., Schumann, G. J.-P., Koch, M., \& Thenkabail, P.S. (2015). Prompt proxy mapping of flood damaged rice fields using MODIS-derived indices. https:// doi.org/10.3390/rs71215805.

16. Arabi Aliabad, F., Shojaei, S., Zare, M., \& Ekhtesasi, M. R. (2019). Assessment of the fuzzy ARTMAP neural network method performance in geological mapping using satellite images and Boolean logic. International Journal of Environmental Science and Technology, 16(7), 3829-3838. https://doi.org/10.1007/ s13762-018-1795-7

17. Nasiri, A., Shirokova, V., Zareie, S., \& Shojaei, S. (2017). Assessment of the status and intensity of water erosion in the river basin delichai (Iranian territory) using GIS model. International Multidisciplinary Scientific GeoConference: SGEM, 17(52), 89-96. https://doi.org/10.5593/SGEM2017/52/S20.012

18. Cheshmidari, M. N., Hatefi Ardakani, A. H., Alipor, H., \& Shojaei, S. (2017). Applying Delphi method in prioritizing intensity of flooding in Ivar watershed in Iran. Spatial Information Research, 2(25), 173-179. https://doi.org/10.1007/S41324017-0086-6

19. Ardakani, A. H. H., Shojaei, S., Siasar, H., \& Ekhtesasi, M. R. (2018). Heuristic evaluation of groundwater in arid zones using remote sensing and geographic information system. International Journal of Environmental Science and Technology, 17(2), 633-644. https://doi.org/10.1007/S13762-018-2104-1

20. Shojaei, S., Kalantari, Z., \& Rodrigo-Comino, J. (2020). Prediction of factors affecting activation of soil erosion by mathematical modeling at pedon scale under laboratory conditions. Science and Reports, 10(1), 1-13. https://doi.org/10.1038/ s41598-020-76926-1

21. Eslami, Z., Shojaei, S., \& Hakimzadeh, M. A. (2017). Exploring prioritized sub-basins in terms of flooding risk using HEC_HMS model in Eskandari catchment, Iran. Spatial Information Research, 25(5), 677-684. https://doi.org/10.1007/s41324-0170135-1

22. De La Cruz, R. M., Olfindo, N. T., Felicen, M. M., Borlongan, N. J. B., DIfuntorum, J. K. L., \& Marciano, J. J. S. (2020). Nearrealtime flood detection from multi-temporal sentinel radar images using artificial intelligence. In International Archives of the Photogrammetry, Remote Sensing and Spatial Information Sciences-ISPRS Archives, 43(B3), 1663-1670. https://doi.org/10. 5194/isprs-archives-XLIII-B3-2020-1663-2020

23. Manjusree, P., Kumar, L. P., Bhatt, C. M., Rao, S., \& Bhanumurthy, V. (2012). Optimization of threshold ranges for rapid flood inundation mapping by evaluating backscatter profiles of high incidence angle SAR images. International Journal of Disaster Risk Science, 2, 113-122. https://doi.org/10.1007/ s13753-012-0011-5

24. Shen, X., Wang, D., Mao, K., Anagnostou, E., \& Hong, Y. (2019). Inundation extent mapping by synthetic aperture radar: A review. Remote Sensing. https://doi.org/10.3390/rs11070879

25. Huang, M., \& Jin, S. (2020). Rapid flood mapping and evaluation with a supervised classifier and change detection in Shouguang using Sentinel-1 SAR and Sentinel-2 optical data. Remote Sensing. https://doi.org/10.3390/rs12132073

26. Cui, B., Zhang, Y., Yan, L., Wei, J., \& Wu, H. (2019). An unsupervised SAR change detection method based on stochastic subspace ensemble learning. Remote Sensing. https://doi.org/10. 3390/rs11111314

27. Lo, S.-W., Wu, J.-H., Lin, F.-P., \& Hsu, C.-H. (2015). Visual sensing for urban flood monitoring. Sensors. https://doi.org/10. 3390/s150820006

28. Giustarini, L., Hostache, R., Matgen, P., Schumann, G. J. P., Bates, P. D., \& Mason, D. C. (2013). A change detection approach to flood mapping in Urban areas using TerraSAR-X.
IEEE Transactions on Geoscience and Remote Sensing, 51(4), 2417-2430. https://doi.org/10.1109/TGRS.2012.2210901

29. Liang, J., \& Liu, D. (2020). A local thresholding approach to flood water delineation using Sentinel-1 SAR imagery. ISPRS Journal of Photogrammetry and Remote Sensing, 159, 53-62. https://doi.org/10.1016/J.ISPRSJPRS.2019.10.017

30. Razavi Termeh, S. V., Kornejady, A., Pourghasemi, H. R., \& Keesstra, S. (2018). Flood susceptibility mapping using novel ensembles of adaptive neuro fuzzy inference system and metaheuristic algorithms. Science of The Total Environment, 615, 438-451. https://doi.org/10.1016/J.SCITOTENV.2017.09.262

31. Falah, F., Rahmati, O., Rostami, M., Ahmadisharaf, E., Daliakopoulos, I. N., \& Pourghasemi, H. R. (2019). Artificial neural networks for flood susceptibility mapping in data-scarce urban areas. Spatial Modeling in GIS and $R$ for Earth and Environmental Sciences. https://doi.org/10.1016/B978-0-12-815226-3. 00014-4

32. Tiwari, V., Kumar, V., Matin, M. A., Thapa, A., Ellenburg, W. L., Gupta, N., \& Thapa, S. (2020). Flood inundation mappingKerala 2018; Harnessing the power of SAR, automatic threshold detection method and Google Earth Engine. PLOS ONE. https:// doi.org/10.1371/journal.pone.0237324

33. Pulvirenti, L., Pierdicca, N., \& Chini, M. (2010). Analysis of Cosmo-SkyMed observations of the 2008 flood in Myanmar. Italian Journal of Remote Sensing, 42(1), 79-90. https://doi.org/ 10.5721/ITJRS20104217

34. Cao, H., Zhang, H., Wang, C., \& Zhang, B. (2019). Operational flood detection using Sentinel-1 SAR data over large areas. Water (Switzerland). https://doi.org/10.3390/w11040786

35. Martinis, S., Twele, A., \& Voigt, S. (2009). Towards operational near real-time flood detection using a split-based automatic thresholding procedure on high resolution TerraSAR-X data. Natural Hazards and Earth Systems Sciences, 9(2), 303-314. https://doi.org/10.5194/NHESS-9-303-2009

36. Zhang, B., Di, L., Yu, G., Shao, Y., Shrestha, R., \& Kang, L. (2013). A web service based application serving vegetation condition indices for flood crop loss assessment. In $20132 \mathrm{nd}$ Int. Conf. Agro-Geoinformatics Inf. Sustain. Agric. Agro-Geoinformatics 2013 (pp. 215-220)https://doi.org/10.1109/ARGOGEOINFORMATICS.2013.6621910

37. Di, L., Yu, E. G., Kang, L., Shrestha, R., \& Bai, Y.-Q. (2017). RF-CLASS: A remote-sensing-based flood crop loss assessment cyber-service system for supporting crop statistics and insurance decision-making. Journal of Integrative Agriculture, 2017(2), 408-423. https://doi.org/10.1016/S2095-3119(16)61499-5

38. Tripathi, P. (2015). Flood disaster in India: An analysis of trend and preparedness. Interdisciplinary Journal of Contemporary Research, 2(4).

39. Inman, V. L., \& Lyons, M. B. (2020). Automated inundation mapping over large areas using Landsat data and google earth engine. https://doi.org/10.3390/rs12081348

40. Rudra, K. (2020). Combating flood and erosion in the lower Ganga plain in India: Some unexplored issues. Disaster Studies, 173-186. https://doi.org/10.1007/978-981-32-9339-7_9.

41. HELP-Water \& Disasters (2020). Principles to address waterrelated disaster risk reduction (DRR) under the COVID-19 pandemic.

42. Bhatt, C. M., Gupta, A., Roy, A., Dalal, P., \& Chauhan, P. (2021). Geospatial analysis of September, 2019 floods in the lower gangetic plains of Bihar using multi-temporal satellites and river gauge data. Geomatics, Natural Hazards and Risk, 12(1), 84-102. https://doi.org/10.1080/19475705.2020.1861113

43. Amani, M., Ghorbanian, A., Ahmadi, S. A., Kakooei, M., Moghimi, A., Mirmazloumi, S. M., Moghaddam, S. H., Mahdavi, S., Ghahremanloo, M., Parsian, S., \& Wu, Q. (2020). Google earth engine cloud computing platform for remote sensing big 
data applications: A comprehensive review. IEEE Journal of Selected Topics in Applied Earth Observations and Remote Sensing, 13, 5326-5350. https://doi.org/10.1109/JSTARS.2020. 3021052

44. Beig, G., \& Ali, K. (2006). Behavior of boundary layer ozone and its precursors over a great alluvial plain of the world: IndoGangetic Plains. Geophysical Research Letters. https://doi.org/ 10.1029/2006GL028352

45. Jha, R. K., \& Gundimeda, H. (2019). An integrated assessment of vulnerability to floods using composite index-A district level analysis for Bihar India. International Journal of Disaster Risk Reduction. https://doi.org/10.1016/J.IJDRR.2019.101074

46. Sinha, R., \& Tandon, S. K. (2014). Indus-Ganga-Brahmaputra Plains: The Alluvial Landscape. World Geomorphological Landscapes. https://doi.org/10.1007/978-94-017-8029-2_5

47. Kumari, N., Srivastava, A., \& Dumka, U. C. (2021). A long-term spatiotemporal analysis of vegetation greenness over the Himalayan region using google earth engine. Climate, 9(7), 1-20. https://doi.org/10.3390/cli9070109
48. Rajesh, S., Nisia, T. G., Arivazhagan, S., \& Abisekaraj, R. (2020). Land cover/land use mapping of LISS IV imagery using object-based convolutional neural network with deep features. Journal of the Indian Society of Remote Sensing, 48(1), 145-154. https://doi.org/10.1007/s12524-019-01064-9

49. Lal, P., Prakash, A., \& Kumar, A. (2020). Google Earth Engine for concurrent flood monitoring in the lower basin of IndoGangetic-Brahmaputra plains. Natural Hazards, 104(2), 1947-1952. https://doi.org/10.1007/s11069-020-04233-z

50. Khan, M. I. (2020) COVID-19: Bihar flood control works stalled amid lockdown. Water, DownToEarth.

51. IFRC (2020) India: Floods final report (DREF $n^{\circ}$ MDRIN026) India I ReliefWeb. International Federation of Red Cross and Red Crescent Societies.

Publisher's Note Springer Nature remains neutral with regard to jurisdictional claims in published maps and institutional affiliations. 